\title{
Proactive personality, voice behavior, and the roles of team social exchange
}

\author{
Nikodemus Hans Setiadi Wijaya \\ STIE YKPN (YKPN School of Business), Yogyakarta, Indonesia \\ Corresponding author: niko.wijaya@gmail.com
}

\begin{tabular}{l} 
Article Info \\
\hline Article history: \\
Received : 28 January 2021 \\
Accepted : 29 February 2021 \\
Published : 1 July 2021 \\
JEL Classification Code: \\
L25, M12, M14 \\
Author's email: \\
niko.wijaya@gmail.com \\
DOI: 10.20885/jsb.vol25.iss2.art5
\end{tabular}

$\underline{\text { DOI. } 10.20885 / \text { jsb.vol25.iss2.art5 }}$

\begin{abstract}
Purpose: This research examined the links of proactive personality, team social exchange comprising leader-member exchange (LMX) and teammember exchange (TMX), and two types of voice behavior comprising team-voice behavior (TVB) and organizational-voice behavior (OVB). Under self-determination theory, the current study proposes the mediating effects of team social exchange on proactive personality and voice behavior.
\end{abstract}

Design/methodology/approach: This study was based on online questionnaire surveys from 238 Indonesian employees. A structural equation modeling (SEM) analysis with the bootstrapping technique was used to examine the hypothesized relationships.

Findings: The current study found 1) the significant influences of proactive personality on both LMX and TMX; 2) the significant influences of proactive personality on TVB and OVB; 3 ) the influences of LMX and TMX on both TVB and OVB; and 4) the partial mediating effects of LMX and TMX.

Research limitation/implications: A single-rater method in data collection may occur in some extents of common method variance (CMV). The findings contribute to the empirical evidence of the pivotal role of team social exchange on the relationships between proactive personality and two types of voice behavior.

Practical implications: Since voice behavior may have positive impacts on the organization's performance and survival, organizations may wish to include proactive attributes in the HRM process (e.g., selection, promotion) and may also want to place more attention on efforts directed at improving team social exchange relationships. Also, organizational practitioners are advised to promote team social exchange as an additional factor impacting voice behavior. In addition, the proposal of two types of voice behavior may offer a wider scope of this construct.

Originality/value: This study proposes two types of voice behavior, namely team-voice behavior (TVB) and organizational-voice behavior (OVB) which extend the scope of this construct.

Keywords: Proactive personality, Team social exchange (LMX and TMX), Team-voice behavior (TVB), Organizational-voice behavior (OVB), Self-determination theory.

\section{Introduction}

Employee voice behavior that relates to the extent to which employees communicate using suggestions, ideas, or information can have very significant impacts on the organization's performance and even its continued existence (Morrison, 2011). Voice behavior is a voluntary 
behavior that focuses on the expression of a constructive challenge with an intention to improve deficiencies rather than only criticize (Van Dyne \& LePine, 1998; Van Dyne et al., 2003). As a part of the extra-role performance (LePine \& Van Dyne, 1998; Morrison, 2011), voice behavior can help teams to accomplish teamwork by giving them the ability to share ideas, knowledge, and insights with other team members (LePine \& Van Dyne, 1998). Prior works have examined the influences of various factors impacting voice behavior. Most of them have focused on contextual environments, for example, access to resources and strategy-related information (Fuller et al., 2006), leadership (Guo et al., 2020), relational quality (Botero \& Van Dyne, 2009; Hsiung, 2012), and job stressors ( $\mathrm{Ng} \&$ Feldman, 2012). Other works have investigated various personal attributes, including locus of control, self-esteem, emotions, and proactive personality (Grant, 2013; Premeaux \& Bedeian, 2003; Tangirala \& Ramanujam, 2008).

Proactive personality refers to a dispositional construct that identifies differences among people in regard to the extent to which they take action to influence their work environments (Bateman \& Crant, 1993). Proactive people express more voice behavior (Seibert et al., 2001) because this behavior may be a way to make meaningful impacts on their environment (Crant \& Bateman, 2000; Van Dyne \& LePine, 1998). Prior research, however, has only emphasized the straightforward effect of personality on voice behavior (Crant et al., 2011; Seibert et al., 2001). Meanwhile, scholars have suggested that the transformation of proactive personality into behavior should be better understood through assessing mediating relationships (Seibert et al., 1999; Thompson, 2005). In this research, it was expected the possibility of team social exchange as a mediator.

A team social exchange, the smallest social scope where employees frequently interact in their daily activities, offers a unique opportunity for contributions of attitude and behavior on the part of team members (Detert \& Burris, 2007; Morrison, 2011; Tse \& Dasborough, 2008). In this research, it was expected that a good team exchange relationship provides open and conducive employment relationships which in turn enhance a sense of greater opportunity for constructive voice (Dundon et al., 2004). Prior studies have only been focused on the tendency of proactive employees to reveal their voice (Seibert et al., 2001). As a consequence, any factors that may improve less proactive employees in this respect have been ignored in investigations. An investigation of the effects of team social exchange is imperative to provide insight into how this factor may improve the voice behavior of both more and less proactive employees.

In a team, social exchange relationships comprise the relationship between an employee and his/her supervisor (labeled as "leader-member exchange") and the relationship between the employee with other team members (labeled as "team-member exchange"). Leader-member exchange (hereafter abbreviated as "LMX") can be defined as the quality of the supervisorsubordinate relationship (Dansereau et al., 1975). LMX characterizes a dyadic relationship where members share mutual trust, respect, reciprocal influence, loyalty, liking, and sense of mutual obligation with their immediate supervisors (Botero \& Van Dyne, 2009; Graen \& Uhl-Bien, 1995). A high-quality LMX relationship brings opportunities for team members to speak up, exchange information, and use more communication channels because they have supervisor support (Botero \& Van Dyne, 2009). Team-member exchange (hereafter abbreviated as "TMX"), on the other hand, is the social exchange of an employee with his/her team members in terms of the reciprocal contribution of ideas, feedback, and assistance (Seers, 1989; Seers et al., 1995). It has been suggested that the quality of TMX is an essential factor that allows members to interact with teammates sufficiently, encouraging them to express their unique ways of thinking (Liao, Liu, \& Loi, 2010). Thus, both LMX and TMX are related to the willingness of employees to communicate or express their thoughts (Botero \& Van Dyne, 2009; Crant, 2000; Fischer et al., 2005; Morrison, 2011).

Van Dyne and LePine (1998) emphasized "voice" as a verbal expression of employees within teams. Employee voice, however, may be delivered at the organizational level (Morrison, 2011). Moreover, it is realized that the willingness of proactive people to make an impact will not be restricted only in the case of their teams, but also in the case of their organizations (Bateman \& Crant, 1993). To extend the scope of voice behavior (e.g., Botero \& Van Dyne, 2009; LePine \& Van Dyne, 1998), in this research, the model used two types of employee voice. First, using the same property as that of Van Dyne and LePine (1998), it was labeled team-voice behavior (later 
abbreviated as "TVB"). Second, in this study, Van Dyne and LePine (1998) voice concept was expanded, i.e. employee voice toward others outside his/her team or group organizational-voice behavior (later abbreviated as "OVB").

Self-determination theory was used as the basis for the research model. This theory suggests that an understanding of human motivation, as it relates to conducting activities, requires a consideration of inborn psychological needs for competence, autonomy, and relatedness (Deci \& Ryan, 2000; Guay et al., 2000; Ryan, 1995). In brief, the objectives of the present research were to examine (1) the direct effect of proactive personality on voice behavior and team social exchange, and (2) the direct effect of team social exchange on voice behavior, and (3) whether team social exchange will mediate the relationships between proactive personality and employee voice behavior (Figure 1).

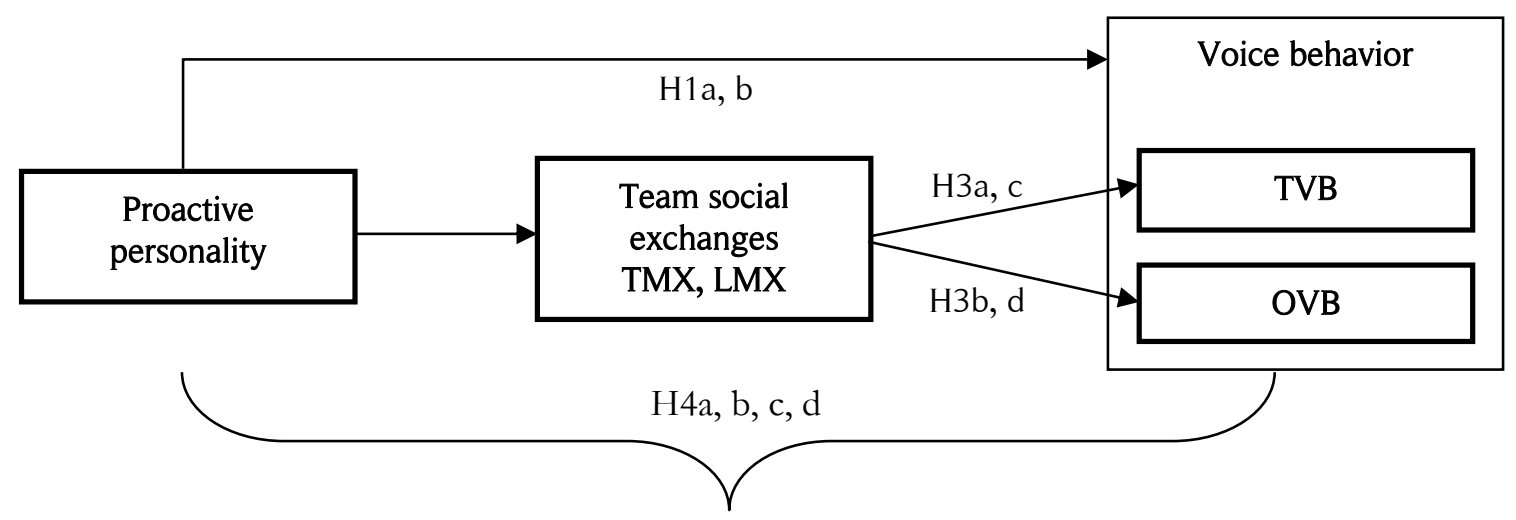

Figure 1. The proposed research model

\section{Literature Review}

\section{Proactive Personality and Voice Behavior}

Voice behavior is a verbal expression intended to convey improvement, not simply to complain (Morrison, 2011). The definition has a positive connotation with regard to verbal expressions because people want to make novel suggestions for change and recommend changes to products, standards, or procedures even when others may contradict (Van Dyne \& LePine, 1998; Van Dyne et al., 2003). As mentioned, in the current research, voice behavior was divided into TVB and OVB. Based on the findings of prior research (Fuller Jr \& Marler, 2009; Seibert et al., 2001), it was expected that there would be a positive influence of proactive personality on both TVB and OVB.

Scholars believed that the more proactive people are, the more willing they are to improve their work environment (Bateman \& Crant, 1993; Crant, 2000) and to have strong personal initiatives beyond routine and formal job requirements (Bateman \& Crant, 1999; Crant, 2000). Moreover, as better players in a challenging working environment (Converse et al., 2012; Crant, 2000; Seibert et al., 2001) and because of the ability to anticipate future conditions (Frese et al., 1996), proactive employees tend to interpret acquired feedback and share it rather than ignoring working issues and trouble within their teams and organizations. As a result, it was expected that proactive employees will exhibit more TVB and OVB as compared to those who are less proactive.

According to self-determination theory, intrinsically motivated behavior can be influenced by aspects of the personality that encourage interest in the behavior itself (Deci \& Ryan, 2000). With a higher degree of self-efficacy and perceived capacity to carry out broader work tasks (Brown et al., 2006; Crant, 2000), proactive employees are more confident about exhibiting voice behavior. Because of a tendency to control rather than be controlled (i.e., an autonomy-oriented behavior, Fuller Jr \& Marler, 2009), highly proactive employees tend to more actively convey their thoughts in order to control their work environment as compared to less proactive employees. For proactive employees, unrewarded actions such as voice behavior (Morrison, 2011; Morrison \& Phelps, 1999) are intrinsically encouraged by their personalities, rather than being selected behavior controlled by external forces (Deci \& Ryan, 2000). To summarize, more highly proactive employees, as compared to those that are less proactive, are predisposed to deliver their voice to both others in (TVB) and 
outside of their teams (OVB) more frequently. Thus:

H1a: Proactive personality will be positively related to TVB.

H1b: Proactive personality will be positively related to OVB.

\section{Proactive Personality, Team Social Exchange, and Voice Behavior}

Proactive personality relates to some traits corresponding with how people deal with their external environment (Bateman \& Crant, 1993). In particular, the authors found the proactive personality scale to be positively correlated with conscientiousness, extraversion, a need for achievement, and a need for dominance. Further, extraversion and the need for dominance are personal traits that correspond to a high need for stimulation, activity, assertiveness, quantity, and intensity in interpersonal interactions or in building relationships within organizations (Bateman \& Crant, 1993; Nikolaou et al., 2008). Past research has confirmed the abilities of proactive persons related to building relationships within organizations (Li et al., 2010; Thompson, 2005).

According to self-determination theory, a proactive personality may correspond to a need for secure relatedness with other people in an environment (Deci \& Ryan, 2000; Vallerand, 2000). Proactive individuals will adjust to dissatisfaction in interpersonal relations through pushing their efforts related to getting this need satisfied (Deci \& Ryan, 2000). Although each supervisor or team member may differ in regard to their level of engaging in team social exchange (Li et al., 2010; Tse \& Dasborough, 2008), proactive individuals are internally reinforced with regard to building and maintaining their relationships with everyone in their organization (Crant, 2000; Gong et al., 2012). This action should lead to a positive response from the other parties concerned (Fuller Jr \& Marler, 2009). Their supervisors or teammates would be expected to express their appreciation by returning similar responses, more or less. These positive responses from supervisors and teammates may lead to a positive perception of the proactive employees of the quality of team social exchange. Therefore, proactive employees are not only better at making relationships with their supervisors (LMX) and teammates (TMX) but also in developing their own perceptions about team social exchange quality. Thus:

H2a : Proactive personality will be positively related to LMX.

H2b: Proactive personality will be positively related to TMX.

Every organization or unit of organization is required to have specific information associated with tasks (Thompson, 2005). Seibert, et al. (2001) found that the extent to which persons have information is influenced by the number of contacts required in organizations. A social exchange relationship also facilitates personal development through a learning process (Arthur, 1994; Botero \& Van Dyne, 2009; Godshalk \& Sosik, 2003; Liden et al., 1993; Major et al., 2006) thus promoting desirable work-related behavior (Chan, 2006; Li et al., 2010). It was believed that a good team social exchange may offer a conducive learning environment for information exchange that allows employees to develop their capability and self-confidence related to effective TVB and OVB.

Mutual support between parties exists in LMX and TMX relationships (Graen \& Uhl-Bien, 1995; Seers, 1989). Self-determination theory suggests that although relational support is not strongly necessary to facilitate intrinsic motivation in people, it remains an intrinsic motivation that encourages their expression (Deci \& Ryan, 2000). In contrast, a sense of helplessness or a lack of environmental support leads to a lack of such motivation (Ryan, 1995). A high quality of team social exchange can promote voice behavior because it maintains a positive signal that voice is both welcome and supported (Detert \& Burris, 2007; Morrison, 2011; Seers, 1989; Van Dyne et al., 2008). Such conditions also offer optimal challenges, opportunities for promoting feedback, and more freedom from demeaning evaluations from others (Ryan \& Deci, 2000). Furthermore, a highquality team social exchange not only makes communication that challenges the status quo less risky (Crant, 2000; Gong et al., 2012) but also improves information accumulation as an important source of ideas for effective voice.

Prior literature on this topic has also suggested that support from supervisors and coworkers enhances individual autonomy (Van Mierlo et al., 2006). In a supportive environment, 
performing TVB and OVB is more likely an interesting activity and is derived autonomously (Deci \& Ryan, 2000). Moreover, since a sense of autonomy is important for extra-role tasks such as voice behavior (Deci \& Ryan, 2000), it was believed that the higher the quality of team social exchange relationships, the more employees will be willing to convey their TVB and OVB. Thus:

H3a : LMX will be positively related to TVB.

H3b: LMX will be positively related to OVB.

H3c: TMX will be positively related to TVB.

H3d: TMX will be positively related to OVB.

As mentioned above, a proactive personality includes characteristics that encourage the development of team social exchange (Hypothesis 2), and team social exchange shapes a pleasant environment for voice behavior (Hypothesis 3). It was thus expected that the influences of proactive personality and voice behavior to be mediated by team social exchange. The argument is in line with prior literature suggesting that (1) highly proactive personalities correspond with the ability to build relationships in any form within organizations (Crant, 2000; Fuller Jr \& Marler, 2009; Li et al., 2010; Thompson, 2005) and (2) these good interactions, in turn, offer a supportive atmosphere for employees that plays a pivotal role in developing spontaneous voice behavior (Gong et al., 2012).

For proactive employees, involvement in exchange relationships within organizations is intended to help them acquire more information as a result of networking (Fuller Jr \& Marler, 2009; Gong et al., 2012; Thompson, 2005) thus improving perceptions related to self-competence and autonomy. Further, these feelings of competence and autonomy are fundamental motivators for conducting activities (Deci \& Ryan, 2000) that, in turn, encourage employees to exhibit voice behavior. This study proposed that the effect of proactive personality on TVB and OVB should be also mediated by LMX and TMX. Since this study previously hypothesized that proactive personality has a direct influence on TVB and OVB (Hypothesis 1), therefore the mediating effects of LMX and TMX to be more likely to be partial rather than full. Thus:

H4a: LMX will partially mediate the relationship between proactive personality and TVB. H4b: LMX will partially mediate the relationship between proactive personality and OVB. H4c: TMX will partially mediate the relationship between proactive personality and TVB. H4d: TMX will partially mediate the relationship between proactive personality and OVB.

\section{Methods}

\section{Participants and Procedure}

The participants in this study were alumni of an Indonesian college. They were working in various companies. An Indonesian questionnaire was administrated. The target participants were geographically dispersed throughout regions in Indonesia, therefore the online questionnaire survey was considered to be an appropriate method. Initially, the online survey was distributed to 900 selected alumni of the university and 242 gave responses. Four participants were found to have submitted double responses. Finally, a total of 238 usable data were used. Fifty four percent of the participants were male. The average age was 31 years, and $48 \%$ of the participants were married. All participants had received an undergraduate degree, and $27 \%$ of them had also completed a master's degree. This indicated that the participants were relatively well-educated. The average job experience, organizational tenure, and team tenure were $6.95,4.61$, and 3.23 years, respectively. Most of the participants were front-line employees (47.9\%), 23.9\% were supervisors, $20.2 \%$ were middle managers, and only $8 \%$ held top management positions.

\section{Measures}

Proactive personality. Ten items of proactive personality scale used in Seibert, et al. (1999) was originally consisting of 17 items (Bateman \& Crant, 1993). A sample item is "I am constantly on the lookout for new ways to improve my life." Participants indicated their responses on a 5-point scale ranging from strongly disagree (1) to strongly agree (5). The Cronbach's alpha for this measure was .89. 
LMX. LMX was assessed with the 7-item scale proposed by Graen and Uhl-Bien (1995). A sample question is "How well does your leader understand your job problems and needs?" Participants indicated their responses on a 5-point scale ranging from not a bit (1) to a great deal (5). Another sample is "How well does your leader recognize your potential?" for which their responses ranged from not at all (1) to fully (5) (see Graen \& Uhl-Bien, 1995, the authors used different answer formats for each question). The Cronbach's alpha for this measure was .85.

TMX. TMX was assessed with the 10-item scale developed by Seers, Petty, and Cashman (Seers et al., 1995). A sample item is "How well do other members of your team recognize your potential?" This scale was measured on a 5-point Likert scale ranging from (1) very little extent to (5) very great extent. The Cronbach's alpha for this measure was .79.

TVB. TVB was assessed with the original 6-item scale of Van Dyne and LePine (1998). A sample item is "I develop and make recommendations concerning issues that affect this workgroup." This scale was measured using a 5-point Likert scale ranging from strongly disagree (1) to strongly agree (5). The Cronbach's alpha for this measure was .77.

OVB. The original scale of Van Dyne and LePine (1998) was modified to measure the extent to which employees engage in voice behavior on behalf of others in their organizations. Like the original one, this scale consisted of 6 items. A sample item is "I speak up and encourage others outside the group to get involved in issues that affect this organization." This scale was also measured using a 5-point Likert scale ranging from strongly disagree (1) to strongly agree (5). The Cronbach's alpha for this measure was .83.

All measures were validated. There were a total number of 39 items making up the main variables. Factor loadings for the items ranged from .45 to .84 , representing acceptable loadings in the sample size of more than 200 (Hair et al., 2010). A test of a five-factor measurement model showed that each item satisfactorily related to its respective factor, with standardized estimates ranging from .33 to .80 (all significant at $\mathrm{p}<.001$ ). The goodness-of-fit outputs for the five-factor model were $\chi^{2}=841.20[633], \chi^{2} / \mathrm{df}=1.33, \mathrm{CFI}=.95$, RMSEA $=.04$. The measurement model demonstrated satisfactory fit indices (Kline, 2005). Since the Cronbach's alphas of all variables exceeded the minimum requirement (.70), all items were used in further analyses.

\section{Result and Discussion}

Table 1 shows the means, standard deviations, and bivariate correlations among the variables. Significant associations of TVB with proactive personality $(\mathrm{r}=.48, \mathrm{p}<0.01), \operatorname{LMX}(\mathrm{r}=.28, \mathrm{p}<.01)$, and TMX $(r=.47, \mathrm{p}<.01)$ were found. Similarly, OVB had significant associations with employee proactive personality $(\mathrm{r}=.47, \mathrm{p}<.01), \operatorname{LMX}(\mathrm{r}=.33, \mathrm{p}<.01)$, and TMX $(\mathrm{r}=.41, \mathrm{p}<.01)$. A high correlation between TVB and OVB was found $(\mathrm{r}=.84, \mathrm{p}<.01)$. This indicates that employees with more voice in their teams also expressed more voice for others outside the teams.

Table 1. Means, Standard Deviations, and Correlations

\begin{tabular}{lccccccc}
\hline Variable & M & SD & 1 & 2 & 3 & 4 & 5 \\
\hline 1. Proactive personality & 4.05 & .48 & $(.89)$ & & & & \\
2. LMX & 3.70 & .61 & $.14^{*}$ & $(.85)$ & & & \\
3. TMX & 3.88 & .43 & $.45^{* *}$ & $.27^{* *}$ & $(.79)$ & & \\
4. TVB & 4.16 & .46 & $.48^{* *}$ & $.28^{* *}$ & $.47^{* *}$ & $(.77)$ & \\
5. OVB & 4.09 & .50 & $.47^{* *}$ & $.33^{* *}$ & $.41^{* *}$ & $.84^{* *}$ & $(.83)$ \\
\hline
\end{tabular}

Note. $\mathrm{N}=238 ;{ }^{*} \mathrm{p}<.05$, two-tailed; ${ }^{*} \mathrm{p}<.01$, two-tailed; Cronbach's alphas are shown in the parentheses.

\section{Hypotheses Testing}

In order to find support for all of the hypotheses, a bootstrapping technique using the AMOS program was applied (Preacher et al., 2007). Bootstrapping is a nonparametric approach that imposes no assumptions according to distribution shape (Dust et al., 2014). When multiple mediators are applied, this technique is not only suitable, but also offers more convenient, precise, and parsimonious measurement (Preacher \& Hayes, 2008). Table 2 shows the results for the 
regression weights, standard errors, critical ratios, and significances of the hypothesized paths. The hypothesized model with standardized regression weights is shown in Figure 2.

Table 2. Estimation of the Regression Weights in the Hypothesized Model

\begin{tabular}{|c|c|c|c|c|c|}
\hline & Estimate & S.E. & C.R. & $\mathrm{p}$ & $\begin{array}{c}\text { Standardized } \\
\text { Estimate }\end{array}$ \\
\hline LMX $\leftarrow$ Proactive personality & .091 & .045 & 2.017 & .044 & .164 \\
\hline TMX $\leftarrow$ Proactive personality & 443 & 086 & 5.153 & *** & .619 \\
\hline TVB $\leftarrow$ Proactive personality & .206 & .079 & 2.612 & .009 & .254 \\
\hline OVB $\leftarrow$ Proactive personality & .259 & .078 & 3.313 & $* * *$ & .315 \\
\hline $\mathrm{TVB} \leftarrow \mathrm{LMX}$ & .175 & .102 & 1.713 & .087 & .119 \\
\hline $\mathrm{OVB} \leftarrow \mathrm{LMX}$ & .290 & .110 & 2.652 & .008 & .196 \\
\hline $\mathrm{TVB} \leftarrow \mathrm{TMX}$ & .626 & .151 & 4.141 & $* * *$ & .551 \\
\hline $\mathrm{OVB} \leftarrow \mathrm{TMX}$ & .382 & .110 & 2.652 & .002 & .333 \\
\hline
\end{tabular}

Note. $\mathrm{N}=238, * * * \mathrm{p}<.001$.

Hypothesis 1 expected that proactive personality will be positively related to TVB (H1a) and OVB (H1b). As presented in Table 2 and Figure 2, proactive personality was positively related to TVB $(\beta=.25, \mathrm{p}<.01)$ and to OVB $(\beta=.32, \mathrm{p}<.001)$. The results supported H1a and H1b. Hypothesis 2 expected that proactive personality will be positively related to LMX (H2b) and TMX (H2b). The results indicated that proactive personality had a positive impact on $\operatorname{LMX}(\beta=.16, \mathrm{p}<.05)$ and on TMX ( $\beta=.62, \mathrm{p}<.001)$. Both H2a and H2b were supported. Hypothesis 3 suggested that LMX will be positively related to TVB $(\mathrm{H} 3 \mathrm{a})$ and OVB $(\mathrm{H} 3 \mathrm{~b})$. The result showed the significant effects of LMX on TVB $(\beta=.12, \mathrm{p}<.1)$ and OVB $(\beta=.20, \mathrm{p}<.01)$. Hypothesis 3 also proposed that TMX will be positively related to TVB $(\mathrm{H} 3 \mathrm{c})$ and $\mathrm{OVB}(\mathrm{H} 3 \mathrm{~d})$. The findings demonstrated that there were significant effects of TMX on TVB $(\beta=.55, \mathrm{p}<.001)$ and OVB $(\beta=.33, \mathrm{p}<.01)$. The results thus provided support for $\mathrm{H} 3 \mathrm{a}, \mathrm{H} 3 \mathrm{~b}, \mathrm{H} 3 \mathrm{c}$, and $\mathrm{H} 3 \mathrm{~d}$.

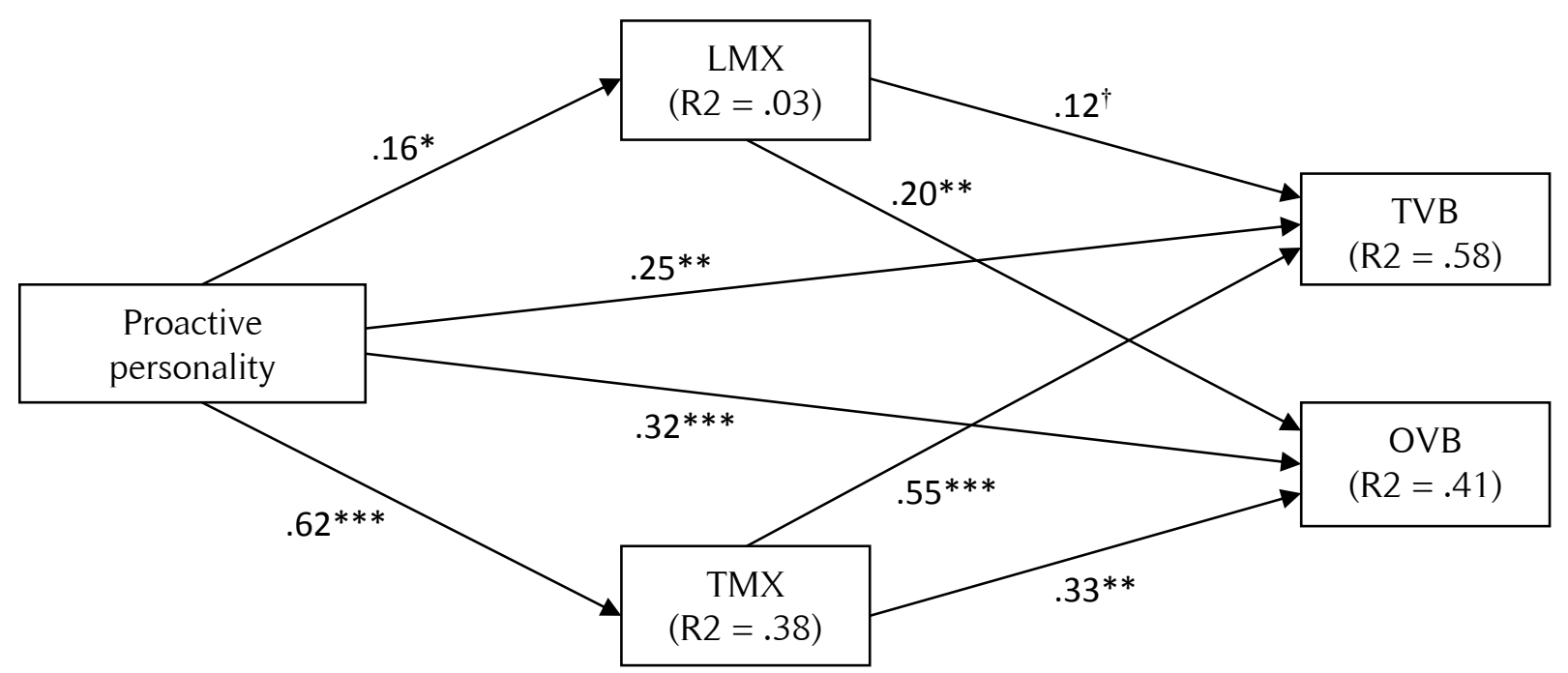

Note. $\mathrm{N}=238 . \dagger \mathrm{p}<.1,{ }^{*} \mathrm{p}<.05,{ }^{* *} \mathrm{p}<.01,{ }^{* * *} \mathrm{p}<.001 . \mathrm{R} 2=$ multiple correlation.

Figure 2. The Hypothesized Model with Standardized Regression Weights

Hypothesis 4 proposed that LMX would partially mediate the relationship between proactive personality and TVB ( $\mathrm{H} 4 \mathrm{a}$ ) as well as the relationship between proactive personality and OVB (H4b). This study also proposed that TMX would partially mediate the relationship between proactive personality and TVB $(\mathrm{H} 4 \mathrm{c})$ as well as the relationship between proactive personality and OVB (H4d). As shown in Table 2 and Figure 2, proactive personality $\rightarrow$ LMX, LMX $\rightarrow$ TVB, and LMX $\rightarrow$ OVB path estimates were significant. As also shown, proactive personality $\rightarrow$ TMX, TMX $\rightarrow$ TVB, and TMX $\rightarrow$ OVB path estimates were also significant. Table 3 shows that the indirect effect of proactive personality on TVB was $.36(\mathrm{p}<.001,95 \% \mathrm{CI}=[.22, .57])$ and on OVB was .23 
$(\mathrm{p}<.01,95 \% \mathrm{CI}=[.09, .42])$. Since proactive personality was found to directly affect both TVB and OVB, the mediating effects of LMX and TMX were partial (Baron \& Kenny, 1986). Therefore, the results supported $\mathrm{H} 4 \mathrm{a}, \mathrm{H} 4 \mathrm{~b}, \mathrm{H} 4 \mathrm{c}$, and $\mathrm{H} 4 \mathrm{~d}$. A goodness-of-fit test of the proposed structural model exhibited satisfactory fit indices: $\chi^{2}=844.70[633], \chi^{2} / \mathrm{df}=1.33$, CFI $=.95$, RMSEA $=.04$.

Table 3. The Results of the Bootstrapping Analysis

\begin{tabular}{lccll}
\hline \multicolumn{1}{c}{ Variable } & LMX & TMX & \multicolumn{1}{c}{ TVB } & \multicolumn{1}{c}{ OVB } \\
\hline Direct effects of proactive personality & $.16^{*}$ & $.62^{* * *}$ & $.25^{* *}$ & $.32^{* * *}$ \\
Direct effects of LMX & - & - & $.12^{\dagger}$ & $.20^{* *}$ \\
Direct effects of TMX & - & - & $.55^{* * *}$ & $.33^{* *}$ \\
Indirect effects of proactive personality via LMX $\left(=.16 \times \beta_{\text {LMX }}\right)^{\text {a }}$ & - & - & .02 & .03 \\
Indirect effects of proactive personality via TMX $\left(=.62 \times \beta_{\text {TMX }}\right)$ b & - & - & .34 & .20 \\
Indirect effects of proactive personality $(\mathrm{a}+\mathrm{b})$ & - & - & $.36^{* * *}$ & $.23^{* *}$ \\
$95 \%$ bootstrapped CI for the indirect effect $(2000$ resamples $)$ & - & - & $(.22, .57)$ & $(.09, .42)$ \\
\hline
\end{tabular}

Note. ${ }^{\mathrm{t}} \mathrm{p}<.1,{ }^{*} \mathrm{p}<.05,{ }^{* *} \mathrm{p}<.01,{ }^{* * *} \mathrm{p}<.001, \mathrm{CI}=$ confidence interval.

\section{Discussion}

The current study aimed to examine both the direct and indirect effects of proactive personality on IVB and OVB. The study included teams LMX and TMX as moderators. A total of 238 pieces of matched data from two waves of surveys 4 months apart were used in the analyses. It was found the positive influences of proactive personality on TVB and OVB. These results were in line with prior studies indicating the importance of employees' proactive personality levels in explaining their voice behavior (Fuller Jr \& Marler, 2009). Moreover, it was found the positive influences of proactive personality on LMX and TMX. These findings are consistent with prior research suggesting the link of this type of personality with people's social behavior (Fuller Jr \& Marler, 2009; Li et al., 2010; Thompson, 2005). In this research, it was discovered that the effect size of proactive personality $\rightarrow$ TMX was much more salient as compared to proactive personality $\rightarrow$ LMX (review Figure 2). This was probably a matter of culture. Supervisors in a high power distance culture, as characterized by our research context, tend to be more comfortable with maintaining status differences with their subordinates (Botero \& Van Dyne, 2009). Although it has been theorized that proactive employees have a strong initiative to form close relationships with their supervisors, most supervisors may tend to keep such relationships somewhat distant. This situation might in turn deteriorate employees' perception of the quality of dyad relationships with their supervisors. Among team members, in contrast, no power difference issue was found to exist. In addition, characterized by a collectivistic culture (i.e., a tendency of looking after each other in exchange for loyalty, Hodgetts \& Luthans, 2000), the initiatives of proactive employees to try to have better relationships with their teammates was very well reciprocated. Further investigations of this evidence may be needed.

Positive influences of LMX and TMX on both types of voice behavior were found. This evidence disclosed the roles of team social exchange on employee voice behavior (see Botero \& Van Dyne, 2009). The effect size of LMX $\rightarrow$ TVB, however, was somewhat weak in regard to comparing the effect size of LMX $\rightarrow$ OVB. A reasonable explanation for this is that high-quality LMX employees might feel that their supervisors are the ones who have the authority to "bail them out" for any actions they take (Graen \& Uhl-Bien, 1995). The reason why the LMX $\rightarrow$ TVB was marginally significant was because in the high power distance culture, team leaders might tend to dominate communication in teams or be less likely to offer many opportunities for members to speak up. We found that the effects of TMX on both types of voice behavior were significant. Contrary to the effects of LMX, the effects of TMX were stronger on TVB as compared to OVB. The results demonstrated that a conducive TMX relationship has a very significant impact on TVB.

Also, the study established the mediating effects of LMX and TMX between proactive personality and voice behavior. The findings demonstrated that the indirect effects of proactive personality on TVB and OVB via LMX and TMX were significant. This study, again indicated that the mediating effects of TMX were stronger than those of LMX. Overall, the findings suggest an 
important role of team social exchange on the relationship between proactive personality and voice behavior.

According to self-determination theory, the sources of intrinsic motivation can consist of both internal and contextual factors. It was suspected that the influences of team social exchange on voice behavior may differ between low- and highly-proactive employees. To seek findings about this notion, we conducted additional regression analysis. The data was split based on low/highly proactive personality levels according to the mean for proactive personality score (mean score of all samples $=$ 4.05). We found 143 participants could be grouped as low-proactive employees and 95 participants were grouped as highly-proactive. One-way ANOVA analysis showed that there was a significant difference between low- and highly-proactive mean scores (F-value $=430.50, \mathrm{p}<.001)$.

By using each of the data sets, LMX and TMX were regressed on TVB, and then on OVB. Gender, age, education, organizational tenure, and level of management were included in all models as controls (LePine \& Van Dyne, 1998). As shown in Table 4, all coefficients were significant for the low-proactive group. For the highly-proactive group, the LMX $\rightarrow$ TVB link was not significant. The major results demonstrated that the positive influences of team social exchange on voice behavior were more robust for the low-proactive group. For this group, environmental context, i.e., team social exchange, could be the main factor influencing their voice behavior. In contrast, the additional findings demonstrated that for the highly-proactive employees, both team social exchange and personality may be important determinants of their voice. In the case of highly proactive employees, however, their personalities may be dominant. The findings implied that highly-proactive employees are not only more able to build exchange relationships, but also they may contribute to enhancing the perceptions of all team members about the quality of the exchange relationship that in turn improves the willingness of all members to express voice.

Table 4. Effects of Team Social Exchange on Voice Behavior: Low versus Highly Proactive Group

\begin{tabular}{lccccc}
\hline & & \multicolumn{3}{c}{ Standardized beta and significance } \\
\cline { 3 - 6 } & $\mathrm{N}$ & LMX $\rightarrow$ TVB & LMX $\rightarrow$ OVB & TMX $\rightarrow$ TVB & TMX $\rightarrow$ OVB \\
\hline Low-proactive employees & 143 & $.19(.017)$ & $.30(.000)$ & $.33(.000)$ & $.21(.010)$ \\
High-proactive employees & 95 & $.16(.122)$ & $.18(.086)$ & $.28(.011)$ & $.23(.040)$ \\
\hline
\end{tabular}

Note. $\mathrm{N}=$ the number of samples. The numbers in the parentheses indicate the significances. To simplify the table, the coefficients of the controls were not reported.

This study provides several implications for theory. First, the present study integrated and examined the links of proactive personality, LMX, TMX, TVB, and OVB. In the present research, team social exchange should be the first major contribution. The findings augmented the factors affecting voice behavior. Second, this research provided empirical evidence of the links among (1) proactive personality $\rightarrow$ TMX and (2) TMX $\rightarrow$ voice behavior. Some of the links included in this study have been assessed by other scholars, i.e., proactive personality $\rightarrow$ LMX, proactive personality $\rightarrow$ voice behavior (i.e., the influences of proactive personality on voice behavior and LMX, e.g., Botero \& Van Dyne, 2009; Fuller Jr \& Marler, 2009; Li et al., 2010). However, the findings should offer a unique perspective of voice behavior for this research analyzed two types of voice behavior. The idea of investigating TVB and OVB should be the second major contribution of this study since it delivers a wider perspective of employee voice. Third, it extended the use of self-determination theory in voice behavior. From the lens of this theory, it explained how personality traits and team social exchange could be self-determining with regard to employee voice. Forth, it delivered new insights through demonstrating the unique influences of proactive personality on LMX, TMX, TVB, and OVB, as well the unique influences of LMX and TMX on TVB and OVB.

\section{Conclusion}

\section{Managerial Implications}

Some implications for practice may also be useful to record. Since this research indicated that 
proactive employees tend to perform more TVB and OVB than less proactive employees, organizations can benefit from proactive personalities through their constructive ideas because such ideas are needed to improve organizational learning ability and innovation (Morrison, 2011) related to dealing with changing and challenging business environments (Fuller Jr \& Marler, 2009). Moreover, proactive employees are inclined to voice organizational scope, they may contribute to organizational development. Through their constructive ideas and concerns, proactive employees may help organizations keep their adaptive posture. More specifically, organizations within creative industries can create proper recruiting, selecting, promoting, and staffing processes involving proactive criteria that might become necessary. In addition, the findings suggest that team social exchange provides significant contributions related to increasing employee TVB and OVB. Leader and member roles in developing LMX and TMX are crucial. Various training programs intended to provide them with interpersonal skills might be very useful. Through managing team social exchange relationships, organizations may also derive constructive ideas from less proactive employees.

\section{Limitations and Directions for Future Research}

This study contains some limitations of this research. First, the study employed a single-rater method. Future research could address this issue by involving both multiple times and raters. For example, supervisors or unit managers can be considered as parties who may be able to assess the level of proactive behavior on the part of employees. Second, LMX was only assessed by subordinates. Since LMX represents employee-supervisor relationships, the information may not depict the actual conditions of such relationships. Future research should involve supervisors in measuring LMX. Third, almost $48 \%$ of the participants were front-line employees. This may have resulted in a lack of generalizability. Future research could employ participants who hold higher positions in their organizations.

Future research also could address the following suggestions to expand the research findings. Cultural profiles of employees should be taken into account since it relates to the psychological process influencing how expectations and sensitivity relate to social exchanges in organizations (Thomas et al., 2003). For example, prior research has examined the influence of cultural profiles on voice behavior (Fischer et al., 2005). In a narrower scope, organizational cultures could be also considered since they influence how employees cope with difficulties of external adaptation and internal integration and that are taught to employees as the adjusted way to perceive, think, and feel in relation to the faced difficulties (Hodgetts \& Luthans, 2000, p. 169). Leadership styles have been investigated as factors impacting employees' motivation for improvement-oriented voice (Detert \& Burris, 2007; Hsiung, 2012). It would be fruitful if future research could explore leader personality (e.g., proactive personality, the Big Five Model of personality) or other leadership styles (e.g., authoritarian, paternalistic, participative) as to whether they encourage or hinder employee voice. Investigating the effect of leader-follower personality congruence on voice behavior might be also interesting (Zhang et al., 2012). In addition, determining how to enhance the voice behavior of less proactive people may still become a flourishing research question. In addressing this issue, some potential factors that could be considered are team norms, team size, and team composition. Lastly, future research could explore specific outcomes of TVB and OVB. A meta-analytic study has previously established the impacts of voice behavior on various individual outcomes ( $\mathrm{Ng} \&$ Feldman, 2012). Future research may expand the outcomes of voice behavior through wider scopes, i.e., at the team/organizational level.

\section{References}

Arthur, M. B. (1994). The boundaryless career: A new perspective for organizational inquiry. Journal of Organizational Behavior, 15(4), 295-306.

Baron, R. M., \& Kenny, D. A. (1986). The moderator-mediator variable distinction in social psychological research: Conceptual, strategic, and statistical considerations. Journal of Personality and Social Psychology, 51(6), 1173-1182. 
Bateman, T. S., \& Crant, J. M. (1993). The proactive component of organizational behavior: A measure and correlates. Journal of Organizational Behavior, 14(2), 103-103.

Bateman, T. S., \& Crant, J. M. (1999). Proactive behavior: Meaning, impact, recommendations. Business Horizons, 42(3), 63-70.

Botero, I. C., \& Van Dyne, L. (2009). Employee voice behavior: Interactive effects of LMX and power distance in the United States and Colombia. Management Communication Quarterly, 23(1), 84-104.

Brown, D. J., Cober, R. T., Kane, K., Levy, P. E., \& Shalhoop, J. (2006). Proactive personality and the successful job search: A field investigation with college graduates. Journal of Applied Psychology, 91(3), 717-726.

Chan, D. (2006). Interactive effects of situational judgment effectiveness and proactive personality on work perceptions and work outcomes. Journal of Applied Psychology, 91(2), 475-481.

Converse, P. D., Pathak, J., DePaul-Haddock, A. M., Gotlib, T., \& Merbedone, M. (2012). Controlling your environment and yourself: Implications for career success. Journal of Vocational Behavior, 80(1), 148-159.

Crant, J. M. (2000). Proactive behavior in organizations. Journal of Management, 26(3), 435-462.

Crant, J. M., \& Bateman, T. S. (2000). Charismatic leadership viewed from above: The impact of proactive personality. Journal of Organizational Behavior, 21(1), 63-75.

Crant, J. M., Kim, T.-Y., \& Wang, J. (2011). Dispositional antecedents of demonstration and usefulness of voice behavior. Journal of Business and Psychology, 26(3), 285-297.

Dansereau Jr, F., Graen, G., \& Haga, W. J. (1975). A vertical dyad linkage approach to leadership within formal organizations: A longitudinal investigation of the role making process. Organizational Behavior and Human Performance, 13(1), 46-78.

Deci, E. L., \& Ryan, R. M. (2000). The "what" and "why" of goal pursuits: Human needs and the self-determination of behavior. Psychological Inquiry, 11(4), 227-268.

Detert, J. R., \& Burris, E. R. (2007). Leadership behavior and employee voice: Is the door really open? Academy of Management Journal, 50(4), 869-884.

Dundon, T., Wilkinson, A., Marchington, M., \& Ackers, P. (2004). The meanings and purpose of employee voice. The International Journal of Human Resource Management, 15(6), 1149-1170.

Dust, S. B., Resick, C. J., \& Mawritz, M. B. (2014). Transformational leadership, psychological empowerment, and the moderating role of mechanistic-organic contexts. Journal of Organizational Behavior, 35(3), 413-433.

Fischer, R., Ferreira, M. C., Assmar, E. M. L., Redford, P., \& Harb, C. (2005). Organizational behaviour across cultures: Theoretical and methodological issues for developing multi-level frameworks involving culture. International Journal of Cross Cultural Management, 5(1), 27-48.

Frese, M., Kring, W., Soose, A., \& Zempel, J. (1996). Personal initiative at work: Differences between East and West Germany. Academy of Management Journal, 39(1), 37-63.

Fuller, J. B., Marler, L. E., \& Hester, K. (2006). Promoting felt responsibility for constructive change and proactive behavior: Exploring aspects of an elaborated model of work design. Journal of Organizational Behavior, 27(8), 1089-1120.

Fuller Jr, B., \& Marler, L. E. (2009). Change driven by nature: A meta-analytic review of the proactive personality literature. Journal of Vocational Behavior, 75(3), 329-345.

Godshalk, V. M., \& Sosik, J. J. (2003). Aiming for career success: The role of learning goal orientation in mentoring relationships. Journal of Vocational Behavior, 63(3), 417-437.

Gong, Y., Cheung, S.-Y., Wang, M., \& Huang, J.-C. (2012). Unfolding the proactive process for 
creativity: Integration of the employee proactivity, information exchange, and psychological safety perspectives. Journal of Management, 38(5), 1611-1633.

Graen, G. B., \& Uhl-Bien, M. (1995). Relationship-based approach to leadership: Development of leader-member exchange (LMX) theory of leadership over 25 years: Applying a multi-level multi-domain perspective. The leadership quarterly, 6(2), 219-247.

Grant, A. M. (2013). Rocking the boat but keeping it steady: The role of emotion regulation in employee voice. Academy of Management Journal, 56(6), 1703-1723.

Guay, F., Vallerand, R. J., \& Blanchard, C. (2000). On the assessment of situational intrinsic and extrinsic motivation: The Situational Motivation Scale (SIMS). Motivation \& Emotion, 24(3), $175-213$.

Guo, Y., Zhu, Y., \& Zhang, L. (2020). Inclusive leadership, leader identification and employee voice behavior: The moderating role of power distance. Current Psychology. 1-10

Hair, J. F., Jr., Black, W. C., Babin, B. J., \& Anderson, R. E. (2010). Multivariate Data Analysis: A Global Perspective (Seventh Edition ed.). New Jersey: Prentice Hall.

Hodgetts, R. M., \& Luthans, F. (2000). International Management: Culture, Strategy, and Behavior (Fourth ed.). Boston: Irvin Mc-Graw-Hill.

Hsiung, H.-H. (2012). Authentic leadership and employee voice behavior: A multi-level psychological process. Journal of Business Ethics, 107(3), 349-361.

Kline, R. B. (2005). Principles and Practice of Structural Equation Modeling (Second ed.). London: The Guilford Press.

LePine, J. A., \& Van Dyne, L. (1998). Predicting voice behavior in work groups. Journal of Applied Psychology, 83(6), 853-868.

Li, N., Liang, J., \& Crant, J. M. (2010). The role of proactive personality in job satisfaction and organizational citizenship behavior: A relational perspective. Journal of Applied Psychology, 95(2), 395-404.

Liao, H., Liu, D., \& Loi, R. (2010). Looking at both sides of the social exchange coin: A social cognitive perspective on the joint effects of relationship quality and differentiation on creativity. Academy of Management Journal, 53(5), 1090-1109.

Liden, R. C., Wayne, S. J., \& Stilwell, D. (1993). A longitudinal study on the early development of leader-member exchanges. Journal of Applied Psychology, 78(4), 662-674.

Major, D. A., Turner, J. E., \& Fletcher, T. D. (2006). Linking proactive personality and the Big Five to motivation to learn and development activity. Journal of Applied Psychology, 91(4), 927-935.

Morrison, E. W. (2011). Employee voice behavior: Integration and directions for future research. The Academy of Management Annals, 5(1), 373-412.

Morrison, E. W., \& Phelps, C. C. (1999). Taking charge at work: Extrarole efforts to initiate workplace change. Academy of Management Journal, 42(4), 403-419.

Ng, T. W. H., \& Feldman, D. C. (2012). Employee voice behavior: A meta-analytic test of the conservation of resources framework. Journal of Organizational Behavior, 33(2), 216-234.

Nikolaou, I., Vakola, M., \& Bourantas, D. (2008). Who speaks up at work? Dispositional influences on employees' voice behavior. Personnel Review, 37(6), 666-679.

Preacher, K. J., \& Hayes, A. F. (2008). Asymptotic and resampling strategies for assessing and comparing effects in multiple mediator models. Behavior Research Methods, 40(3), 879-891.

Preacher, K. J., Rucker, D. D., \& Hayes, A. F. (2007). Addressing moderated mediation hypotheses: Theory, methods, and prescriptions. Multivariate Behavioral Research, 42(1), 185-227.

Premeaux, S. F., \& Bedeian, A. G. (2003). Breaking the silence: The moderating effects of self- 
monitoring in predicting speaking up in the workplace. Journal of Management Studies, 40(6), 1537-1562.

Ryan, R. M. (1995). Psychological needs and the facilitation of integrative processes. Journal of Personality, 63(3), 397-427.

Ryan, R. M., \& Deci, E. L. (2000). Self-determination theory and the facilitation of intrinsic motivation, social development, and well-being. American Psychologist, 55(1), 68-78.

Seers, A. (1989). Team-member exchange quality: A new construct for role-making research. Organizational Behavior and Human Decision Processes, 43(1), 118-135.

Seers, A., Petty, M. M., \& Cashman, J. F. (1995). Team-member exchange under team and traditional management: A naturally occuring quasi-experiment. Group \& Organization Management, 20(1), 18-38.

Seibert, S. E., Crant, J. M., \& Kraimer, M. L. (1999). Proactive personality and career success. Journal of Applied Psychology, 84(3), 416-427.

Seibert, S. E., Kraimer, M. L., \& Crant, J. M. (2001). What do proactive people do? A longitudinal model linking proactive personality and career success. Personnel Psychology, 54(4), 845-874.

Seibert, S. E., Kraimer, M. L., \& Liden, R. C. (2001). A social capital theory of career success. The Academy of Management Journal, 44(2), 219-237.

Tangirala, S., \& Ramanujam, R. (2008). Exploring nonlinearity in employee voice: The effects of personal control and organizational identification. Academy of Management Journal, 51(6), 1189-1203.

Thomas, D. C., Au, K., \& Ravlin, E. C. (2003). Cultural variation and the psychological contract. Journal of Organizational Behavior, 24(5), 451-471.

Thompson, J. A. (2005). Proactive personality and job performance: A social capital perspective. Journal of Applied Psychology, 90(5), 1011-1017.

Tse, H. H. M., \& Dasborough, M. T. (2008). A study of exchange and emotions in team member relationships. Group \& Organization Management 33(2), 194-215.

Vallerand, R. J. (2000). Deci and Ryan's self-determination theory: A view from the hierarchical model of intrinsic and extrinsic motivation. Psychological Inquiry, 11(4), 312-318.

Van Dyne, L., Kamdar, D., \& Joireman, J. (2008). In-role perceptions buffer the negative impact of low LMX on helping and enhance the positive impact of high LMX on voice. Journal of Applied Psychology, 93(6), 1195-1207.

Van Dyne, L., \& LePine, J. A. (1998). Helping and voice extra-role behaviors: Evidence of construct and predictive validity. Academy of Management Journal, 41(1), 108-119.

Van Dyne, L., Soon, A., \& Botero, I. C. (2003). Conceptualizing employee silence and employee voice as multidimensional constructs. Journal of Management Studies, 40(6), 1359-1392.

Van Mierlo, H., Rutte, C. G., Vermunt, J. K., Kompier, M. A. J., \& Doorewaard, J. A. M. C. (2006). Individual autonomy in work teams: The role of team autonomy, self-efficacy, and social support. European Journal of Work and Organizational Psychology, 15(3), 281-299.

Zhang, Z., Wang, M. O., \& Shi, J. (2012). Leader-follower congruence in proactive personality and work outcomes: The mediating role of leader-member exchange. Academy of Management Journal, 55(1), 111-130. 